Session 3248

\title{
An Academic Partnership with Industry: A Win-Win Situation
}

\author{
Peter R. Schuyler, Kenneth Quinn \\ University of Hartford / New Horizons Corporation
}

\begin{abstract}
Technology is a rapidly changing field, it is monumental task for a college or university to keep pace with these changes. As corporate demand for specialized computer hardware and software training increases, it is becoming very challenging to find and retain full time faculty to teach in these areas, and to effectively integrate rapidly changing technology into our curricula. The University of Hartford's S.I. Ward College of Technology has engaged in a successful strategic partnership with New Horizons Corporation to provide specialized computer training for students. This collaboration has provided the University and New Horizons with the ability to offer Microsoft ${ }^{\circledR}$ certified training and certification testing for our students while earning University of Hartford credit. This program allows the University to keep pace with the changing technology needs of potential employers of our graduates while not requiring a significant investment of resources. This program has the potential to provide several significant outcomes; it can improve enrollment, increase corporate visibility of S.I. Ward College of Technology, offer our students marketable skills, serve local industry by providing lifelong educational opportunities for employees, and create a new income for the college. These outcomes have helped to foster an expanding and advantageous relationship between industry and engineering technology. This paper will outline the necessary steps to initiate, develop, assess, and gain university approval for these types of collaborative education agreements. These agreements between industry and academia can help us to meet today's demand for rapidly changing technological educational needs.
\end{abstract}

Introduction

Technology and technology education are rapidly changing fields. It is a significant challenge for programs and higher education institutions to maintain pace with industry and its needs. As corporate demand for specialized computer hardware and software training increases, it is becoming very challenging to find and retain full time faculty to teach in these areas. It is also difficult to respond quickly and effectively to integrate rapidly changing technology into our curricula. The University of Hartford's S.I. Ward College of Technology has engaged in a successful strategic partnership with New Horizons Corporation to help address these issues. This collaboration has provided the University and New Horizons with the ability to offer specialized computer software and hardware training and certification for our students. This program has had several significant outcomes thus far; it has improved enrollment, increased corporate visibility of Ward College, offered our students marketable skills, served local industry by providing lifelong educational opportunities for employees, awarded university credit for these courses, and generated income for the college. These outcomes have helped to foster an expanding and advantageous relationship between industry and engineering technology. New Horizons considers this a novel approach to a strategic partnership with the University of Hartford. New Horizons the World's Leader in IT and Applications training across the globe has worked with the University to establish an ongoing relationship. In moving forward with our partnership we only hope we can add new programs to enhance the attendance and give students proper certifications to increase their earning potential and make each student more marketable to corporate industry.

Discussion

This partnership between University of Hartford and New Horizons Corporation was initiated in the spring of 2002 with New Horizons contacting the Dean of Ward College of Technology. In the summer of 2002 a plan began to take shape and progress was made as we proposed the program to university officials. Concurrently several individuals at the college were trying to identify a suitable college or program that could act as a home for the curriculum and while discussing a variety of pedagogical methodologies suitable to deliver the material. University administrators agreed that program had merit and we were given the blessing to move forward with initial the development of the program. We began the planning of the program by selecting courses that industrial contacts and New Horizons suggested were in great demand by employers. Interest in the program grew rapidly because

"Proceedings of the 2003 American Society for Engineering Education Annual Conference \& Exposition Copyright (C)2003, American Society for Engineering Education" 
several area employers would now reimburse for these types of courses since they being offered by the University and would earn college credit. Table I represents the initial selection of courses offered as part of the program.

TABLE I

JOINT UNIVERSITY OF HARTFORD AND NEW HORIZONS COURSE OFFERINGS

\begin{tabular}{cl}
\hline COURSE:[CREDITS] & \multicolumn{1}{c}{ TITLE } \\
\hline STW 391:[1] & Microsoft Windows 2000 Network Operating Systems Essentials-MS2151 \\
STW 392:[2] & Implementing Microsoft Windows 2000 Professional and Server-MS2152 \\
STW 392:[2] & Implementing Microsoft Windows 2000 Network Infrastructure-MS2153 \\
STW 394:[2] & Implementing \& Administering a Microsoft Windows 2000 Directory Service-MS2154 \\
STW 490:[2] & Designing a Secure Microsoft Windows 2000 Network-MS2150 \\
STW 491:[1] & Designing a Microsoft Windows 2000 Directory Services Infrastructure-MS1561 \\
STW 492:[1] & Designing a Microsoft Windows 2000 Networking Services Infrastructure-MS1562 \\
STW 493:[2] & Administering a Microsoft SQL Server 2000 Database-MS 2072 \\
STW 494:[2] & Programming a Microsoft SQL Server 2000 Database -MS 2073 \\
\hline
\end{tabular}

The next step was identifying the facilities necessary to teach the courses. It was decided that the best location to run these courses would be at the local New Horizons office. This decision was made since New Horizons had numerous excellent classroom facilities and computer laboratories, as well as having the ability to devote entire laboratories and hardware to the courses. Ward College's computer laboratories would be unsuitable since they are multi-use facilities that are shared by several programs and scheduled in traditional one to one and a half hour time blocks. This also led us into a discussion of which faculty would teach the courses, University of Hartford faculty, New Horizons faculty or a combination of both? We ultimately choose to use instructors from New Horizons since they were already Microsoft certified instructors, had been through rigorous training, and had hands on experience with these courses. With these decisions made, we then embarked on the next step of negotiating a revenue sharing agreement between New Horizons and the University. When we reached a acceptable agreement we then began the tenuous task of creating the outlines for the individual courses and began the process of gaining university approval for the courses.

This represented the first major hurdle for the program. A college wide debate began on whether or not these were suitable courses that should be offered by a TAC of ABET accredited institution. The debate was centered on three major concerns brought forth by the faculty.

The first concern was the issue of education verses training, and the debate that surrounds this topic. This debate has existed in engineering and engineering technology schools and colleges for decades and resurfaces periodically as new topics and material come to light and the demands from industry change and often focus on specialized technical skills. Many faculty felt that these courses represented "training" and not "education" and our offering them might damage the reputation of the college and somehow jeopardize our accreditation. Some of the foundations of this belief are grounded in the culture and history of the college. Ward College as evolved from a vocational school of electronics to becoming a college with an enrollment over three hundred students offering five programs of study of which three are TAC of ABET accredited. The college is part of the University of Hartford, which also has a separate College of Engineering. It has taken significant time to shed the vocational school reputation and the faculty was worried that offering these courses may send a negative message that we are returning to training centered model. Although the courses are based on "technical training", students learn a variety of software and software related skills and the content they provide is in high demand by both local, national, and even worldwide industry. Ultimately this argument and the support of the College's Board of Visitors and the endorsement of individual program's Industrial Advisory boards led the faculty to agree that this type of training was valuable. Recently the American Council on Education endorsed these types of Microsoft certification courses for college and transfer credit. ${ }^{1}$

The second concern of the faculty was surrounding the quality control of these courses. The faculty brought forth numerous valid concerns and questions. Among these were; What are the qualifications of the faculty that are teaching these courses and do they meet ABET criteria? How would we maintain control of the content of these courses when they are being run by New Horizons as an outside contractor and the instructors are paid by New Horizons and not the college? How can we insure that the material being taught is current and is the industry standard?.

\section{"Proceedings of the 2003 American Society for Engineering Education Annual Conference \& Exposition Copyright} (C)2003, American Society for Engineering Education" 
We answered the first question of faculty qualifications by explaining that all of the instructors of these courses are first and foremost Microsoft certified instructors. The training and certification to teach these courses is very strictly administered by Microsoft and the instructors undergo very rigorous training and we are confident that these instructors are experts in the areas they teach. Furthermore, New Horizons is well recognized and enjoys a good reputation. New Horizons is also a for profit company and has the ability to maintain a very high quality standard for its instructors often beyond what we can achieve in higher education. To address the ABET concerns, we feel that this is very specialized technical skill and knowledge area and although many of the instructors do not have terminal degrees they can demonstrate proficiency and expertise in their field. This is addressed in section I.F.3 of the 20022003 TAC of ABET Criteria "faculty members teaching technical skills are not required to have advanced degrees but are expected to be masters of their craft" and we feel that these faculty meet the spirit of that statement. ${ }^{2}$

When addressing the questions of maintaining control over the content and it currency we explained that Microsoft certification courses have a very detailed and well-defined curriculum and set of course material for their courses. They require a strict adherence to the curriculum by instructors, and give very little latitude to the instructor to deviate from the prescribed curricula. To insure currency, Microsoft will only support courses for a short period of time and requires vendors and their instructors to stay current and teach the latest courses and this requires constant retraining. If instructors do not follow the course materials or curriculum it is likely that students would not be successful in obtaining certification. As a for profit company New Horizons has a vested interest in students becoming certified for several reasons. The first being that students are more likely to return for more training if they are successful in getting certification. Secondly New Horizons will be unable to continue their relationship with Microsoft if too large a percentage of students are unsuccessful at becoming certified or if the facility is identified as being weak through complains or substandard evaluations.

The third concern was greatest obstacle when we were seeking college and university approval. This concern was centered on the pedagogy and assessment procedures employed in these courses. These courses are geared to working professionals and not towards full time university students. The courses are offered in daylong classes that run several days to one-week in length. This presents a very different pedagogical model than traditionally used at our college and most other higher education institutions. The grading method is pass/fail for these courses. Students are not required to do any homework or hand in any assignments for the courses and the sole form of assessment is the certification exam. Students receive university credit for the course only after successfully taking the certification test. The students may take the certification test at any Microsoft certified testing center any time after they complete the course. Much like the bar exam or many of the other standardized exams students may wait to take the exam until they feel they are ready and are permitted to retake the exam several times at their own cost.

The faculty had many reservations about this model. They were very concerned that the sole form of assessment was the certification test. This model presented very little means of intervention or monitoring if students are not keeping up with the course. Although the students are required to do a variety of laboratory exercises throughout the course, and these act as a gage of student understanding, they are meant more as demonstration tools rather than assessment benchmarks. Since these courses are intensive the opportunities for assessment are limited. The course materials do have many self-tests and assessment exercises as well as a variety of traditional study aids incorporated into the texts.

Since these courses are currently focused towards working professionals we have found that the students are significantly more motivated and stay on top of the work. This is probably as a direct result of their maturity and a better understanding of the value of the courses. They may also be influenced as a result of the fact that many of them will not be reimbursed by their employers for the significant expense of these courses unless they pass the certification exam.

As a result of the intensive teaching methodology and the short time frame over which these courses are taught makes it very difficult for the majority of full time students to enroll in them, although it does not prevent them from taking theses course during semester breaks or during the summer, and some students have expressed interest in doing so. We are currently working on scenario which would allow main campus full-time students the ability to enroll in these courses. If we can create a significant interest on campus for these courses we believe that we could teach them on campus and during a longer timeframe, and teach several courses in a package lasting an entire semester. Although full-time student's tuition would not cover these courses, students would receive a significant

\footnotetext{
"Proceedings of the 2003 American Society for Engineering Education Annual Conference \& Exposition Copyright (C2003, American Society for Engineering Education"
} 
discount. We are investigating several areas for improvement, including adding a grading system, semester long course sequences, and inclusion under university tuition.

Conclusion

This program is currently a work in progress, the college and university ultimately approved it and it has been in place for a little more than one year as of this writing. We are working to improve the program and hope to expand it in the future. In table II you will find a recommended plan for initiating relationship similar to ours, and the steps we followed.

\section{TABLE II}

\section{RECOMMENDATIONS FOR INITIATING A EdUCATION COLLABORATION BETWEEN INDUSTRY AND ACADEMIA}

\begin{tabular}{cl}
\hline STEP & \multicolumn{1}{c}{ RECOMMENDATIONS } \\
\hline I & Identification of new curriculum component or educational need by area industry \\
II & Location of Industry partner to act as collaborator \\
III & Preliminary planning including approval by both corporate and academic administration \\
IV & Resource and facilities plan for implementation \\
V & Negotiation of revenue sharing plan and final administrative approval \\
VI & Course creation and academic approval process \\
VII & Marketing and Implementation of courses \\
VIII & Assessment and improvement of the model \\
\hline
\end{tabular}

The courses have begun to serve the target population and we feel that they have been an asset to the college. Our industrial advisory board has embraced the idea, and has suggested that we market the program more aggressively. The College, University, and New Horizons Corporation jointly share revenue from these courses and this has led us to the possibility of extending this program to a nationwide or global audience. We have reached agreements with several area employers to act as educational liaisons with New Horizons to introduce are greater variety of courses. We have begun the process of exploring the possible creation of degree program surrounding these courses as well that would be sponsored jointly by the University and New Horizons Corporation. We envision the University of Hartford offering university credit though a distance education format with the cooperation of the worldwide network of New Horizons offices that teach these courses.

We have identified several areas for work in future for this program. We would like to integrate these courses into several of our existing program curricula and would like to find a more suitable and mainstream means of not only teaching but assessing these courses. We are also investigating building a degree program around this material as either an expansion of our existing programs or an addition to them, at either the graduate or undergraduate level. We would also like to expand the offerings to include more courses encompassing a greater breadth of material and content.

We believe that this initiative will prove to be a significant revenue generator for the college and university and allow us to fund initiatives we would not have been able to do otherwise. This has offered Ward College an opportunity for growth and recognition. New Horizons considers this a novel approach to a strategic partnership with the University of Hartford. New Horizons the World's Leader in IT and Applications training across the globe will continue to establish and foster ongoing relationships across the US and worldwide. In moving forward with our partnership we only hope we can add new programs to enhance the attendance and give students proper certifications to increase potential income and make each student more marketable to corporate industry.

"Proceedings of the 2003 American Society for Engineering Education Annual Conference \& Exposition Copyright (C2003, American Society for Engineering Education” 


\section{References}

1. American Council on Education College Credit Recommendation Service, http://www.acenet.edu/calec/corporate/certif-exam.cfm (O2002

2. 2002-2003 Criteria for Accreditation of Engineering Technology Programs, TAC of ABET @2001

PETER R. SCHUYLER- is the currently the Assistant Dean of Ward College of Technology at the University of Hartford. He also serves as an Assistant Professor and Chair of the Electronic \& Computer Engineering. He has earned a Bachelor of Science in Bioengineering and a Master of Science \& C.A.S in Electrical Engineering from Syracuse University. He is currently in the final stages of completing the requirements for his doctorate in Higher Education Administration at the University of Massachusetts-Boston.

KENNETH J. QUINN, has been a Sr. Account Executive at New Horizons CLC of Hartford for the last 7 years. Ken has been responsible for forging relationships with several Educational Institutions in the State of Connecticut ranging from staff development to offering classes at New Horizons in various topics, such as complicated Technical training in the Windows 2000 Server environment to Web Development. 